\title{
Um Relato de Atendimento Psicossocial à Família do Acusado de Abuso Sexual
}

Un Relato de Atención Psicosocial a la Familia del Acusado de Abuso Sexual

A Report of Psychosocial Care to the Family of the Accused of Sexual Abuse

Simone de Souza Santos

ORCID: https://orcid.org/0000-0002-2757-4480 Universidade Federal do Espírito Santo, Espírito Santo/Brasil

Edinete Maria Rosa

ORCID: https://orcid.org/0000-0003-4279-8308 Universidade Federal do Espírito Santo, Espírito Santo/Brasil

Elisa Avellar Merçon-Vargas

ORCID: https://orcid.org/0000-0003-1229-3122

Declaração de Direito Autoral

A submissão de originais para este periódico implica na transferência, pelos autores, dos direitos de publicação impressa e digital. Os direitos autorais para os artigos publicados são do autor, com direitos do periódico sobre a primeira publicação. Os autores somente poderão utilizar os mesmos resultados em outras publicações indicando claramente este periódico como o meio da publicação original. Em virtude de sermos um periódico de acesso aberto, permite-se o uso gratuito dos artigos em aplicações educacionais e científicas desde que citada a fonte conforme a licença CC-BY da Creative Commons.

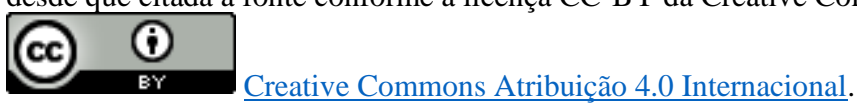

\section{Resumo}

A vivência de situações de abusos sexuais reverbera nas vidas dos vitimados e da família, ocasionando, por exemplo, afastamento social e vergonha. Todavia, pouca atenção é dada à família do acusado. Em vista disso, este artigo tem como objetivo relatar a experiência do projeto de estágio "Apoio e Fortalecimento de vínculos familiares", no qual foi realizado atendimentos psicossociais a senhora A (37 anos), esposa de um acusado de abuso sexual. Foram realizados 25 atendimentos individuais semanalmente com duração de aproximadamente 60 minutos cada. Inicialmente, surgiram questões relacionadas à denúncia; porém, no transcorrer dos atendimentos, outras demandas foram trazidas. Assim, os atendimentos foram divididos nos seguintes blocos temáticos: (a) acolhimento e compreensão da demanda; (b) questões interpessoais após a denúncia; (c) fortalecimento de vínculos; (d) crenças e identidade pessoal; e (e) fortalecimento pessoal. As questões trazidas pela cliente foram semelhantes às encontradas na literatura com relação à familiares de vítimas de abuso sexual, incluindo o sentimento de isolamento social e de vergonha. A denúncia de abuso sexual infantil contra o marido possuiu impacto profundo em diversas esferas da vida da cliente. Concluímos que a escuta qualificada e o atendimento psicossocial são imprescindíveis. Ressaltamos a importância de compreender de modo sistêmico os contextos e relações em que estão inseridos não apenas as vítimas e acusados da violência, mas também seus familiares. Destacamos a importância do apoio social e do fortalecimento da vinculação familiar no processo de enfrentamento da situação de denúncia de abuso, bem como a importância do apoio profissional.

Palavras-chaves: Abuso sexual; Família; Atendimento psicossocial; Relato de experiência. 


\title{
Resumen
}

La experiencia de situaciones de abuso sexual repercute en la vida de las víctimas y de la familia, causando, por ejemplo, retraimiento social y vergüenza. Sin embargo, se presta poca atención a la familia del acusado. En vista de esto, este artículo tiene como objetivo relatar la experiencia del proyecto de pasantía "Apoyo y fortalecimiento de los lazos familiares", en el que se brindó atención psicosocial a la Sra. A (37 años), esposa de un acusado de abuso sexual. Hubo 25 consultas individuales semanales que duraron aproximadamente 60 minutos cada una. Inicialmente, surgieron problemas relacionados con la denuncia; sin embargo, durante la asistencia, se presentaron otras demandas. Así, los servicios se dividieron en los siguientes bloques temáticos: (a) recepción y comprensión de la demanda; (b) problemas interpersonales después de la denuncia; (c) fortalecimiento de los lazos; (d) creencias personales e identidad; y (e) empoderamiento personal. Las cuestiones planteadas por la cliente fueron similares a las encontradas en la literatura sobre los familiares de las víctimas de abuso sexual, incluidos los sentimientos de aislamiento social y vergüenza. La denuncia de abuso sexual infantil contra su esposo tuvo un profundo impacto en varias esferas de la vida de la cliente. Concluimos que la escucha calificada y la atención psicosocial son esenciales. Subrayamos la importancia de comprender sistemáticamente los contextos y las relaciones en los que se insertan no solo las víctimas y los acusados de la violencia, sino también sus familias. Destacamos la importancia del apoyo social y el fortalecimiento de los lazos familiares en el proceso de hacer frente a la situación de la denuncia de abuso, así como la importancia del apoyo profesional.

Palabras clave: Abuso sexual; Familia; Atención psicosocial; Relato de experiencia.

\begin{abstract}
The experience of sexual abuse accusations reverberates in the lives of the victims and the family, causing, for example, social withdrawal and embarrassment. However, little attention is given to the accused's family. Considering that, this article aimed at reporting an experience part of the internship project "Support and Strengthening of Family Bonds", in which psychosocial care was provided to Mrs. A (37 years old), wife of an accused of sexual abuse. A total of 25 individual meeting weekly were conducted lasting approximately 60 minutes each. Initially, issues related to the accusation were addressed; however, other topics emerged throughout the meetings. Hence, the meetings were divided into the following thematic blocks: (a) rapport and demand understanding; (b) interpersonal issues after the accusation; (c) strengthening of bonds; (d) personal beliefs and identity; and (e) personal empowerment. The issues raised by the client were similar to those found in the literature regarding victims of sexual abuse family members, including feelings of social isolation and embarrassment. The accusation of child sexual abuse against the husband had a profound impact on several spheres of the client's life. We conclude that qualified listening and psychosocial care are essential. We underscore the importance of systemically understanding the contexts and relationships in which not only the victims and the accused of violence are inserted but also their families. We call attention to the importance of social support and the strengthening of family ties in the process of coping with the abuse accusation, as well as the importance of professional support.
\end{abstract}

Keywords: Sexual abuse; Family; Psychosocial care; Experience report.

\section{Introdução}

Um levantamento feito pelo Ministério da Mulher, da Família e dos Direitos Humanos (MMFDH, 2019) sobre as denúncias que chegam aos canais do Sistema de Ouvidoria
Nacional de Direitos Humanos e Atendimento (Disque 100, Clique 100, ODNH, Ouvidoria Online e app Proteja Brasil) verificou que foram registradas 76.216 queixas relacionadas a alguma violação dos direitos da criança e do adolescente no ano de 2018. Dentre essas 
denúncias estavam práticas de violências físicas, negligências, violências psicológicas e sexuais. Especificamente, denúncias de violência sexual, foco desse trabalho, representaram cerca de $11 \%$ (8.552) do total de denúncias. Essas denúncias apontadas pelo MMFDH evidenciam que, para uma parte das crianças e adolescentes, os direitos preconizados no Estatuto da Criança e do Adolescente (ECA) nem sempre são garantidos. De acordo com o artigo $5^{\circ}$ do ECA, "Nenhuma criança ou adolescente será objeto de qualquer forma de negligência, discriminação, exploração, violência, crueldade e opressão, punido na forma da lei qualquer atentado, por ação ou omissão, aos seus direitos fundamentais" (Lei n. 8.069, 1990).

Violações aos direitos fundamentais da criança e do adolescente implicam em um sofrimento que deve ser evitado. Os abusos sexuais são um exemplo disso, ao gerarem efeitos negativos na vida física e psicológica das crianças e adolescentes (como dores abdominais, falta de ar, alterações neurológicas, depressão, ansiedade, agressividade, TEPT, psicopatologias, sentimento de culpa, etc.), tendo também um impacto significativo em suas relações sociais e familiares (Campos, Schor, Laurentiz, Santos, \& Peres, 2005; Florentino, 2015; Lima, 2018). A violência sexual envolve uma relação de poder, na qual o abusador está em uma etapa de desenvolvimento superior à vítima em diversos aspectos, dentre eles o sexual. Ao contrário do que comumente imagina-se, o abuso sexual nem sempre envolve o contato físico ou o intercurso sexual, podendo ser perpetuado também por meio de exposição à imagens pornográficas, do toque, do voyeurismo (definido como prazer sexual desenvolvido a partir da visão de atos de cunho sexual; Florentino, 2015), de carícias, entre outras formas (Araújo, 2002; De Antoni, Yunes, Habigzang, \& Koller, 2011; Lima \& Alberto, 2016; Santos \& Dell'Aglio, 2010, 2013).

Os abusos sexuais podem ocorrer tanto nos âmbitos intra como nos extrafamiliares. Nos intrafamiliares, o abusador é uma pessoa próxima da vítima, com laços afetivos ou de parentesco (e.g., pai ou padrasto); este tipo de abuso é mais comum e as vítimas geralmente são meninas, apesar de ocorrer também com meninos (Araújo, 2002; Dell'Aglio, Moura, \& Santos, 2011; Vieira, 2018). Por outro lado, os abusos extrafamiliares ocorrem normalmente em lugares próximos de onde a vítima mora e é cometido por desconhecidos ou pessoas com poucas relações com a família da criança (Costa, Rocha, \& Cavalcante, 2018; De Antoni et al., 2011; Pincolini \& Hutz, 2014; Pincolini, Hutz, \& Laskoski, 2012).

Abusos sexuais geram efeitos significativos nos vitimados e nas famílias. Dentre os sintomas que acometem as vítimas estão: comportamentos agressivos, isolamento social, presença de Transtorno de Estresse PósTraumático, dificuldades de aprendizagem, presença de doenças sexualmente transmissíveis, comportamento sexual inadequado para a idade, comportamentos regressivos a estágios de desenvolvimento anteriores, etc. (Costa, Penso, Rufini, Mendes, \& Borba, 2007; Hohendorff, Santos, \& Dell'Aglio, 2015; Marafon \& Scortegagna, 2017). Além disso, os familiares (principalmente a figura materna) podem se sentir confusos, desamparados e desassistidos (Cunha \& Dutra, 2019; Dell'Aglio et al., 2011).

Com todo esse quadro, a família (membros não abusadores) é vista como um importante ponto de apoio para o enfrentamento e superação das etapas que envolvem as denúncias e a situação traumática (Marafon \& Scortegagna, 2017). Por ser a mãe um dos principais pontos de suporte, ela também necessita de apoio devido à forte carga emocional que recai sobre ela. As mães também podem apresentar sentimentos como raiva, culpa e revolta devido à situação de abuso, bem como algumas crenças pessoais disfuncionais ligadas ao sentimento de culpa, por exemplo (Dell'Aglio et al., 2011; Marafon \& Scortegagna, 2017). Beck (2014) define crenças pessoais como um sistema de pensamentos e ideias que são fundamentadas ao longo da história do indivíduo. Estas irão influenciar a forma como o indivíduo interpreta 
as situações do cotidiano, bem como orientar seu comportamento. Por sua vez, as crenças disfuncionais são aquelas que não passam por uma avaliação realista da situação, sendo passíveis de mudança ao longo do tratamento psicoterapêutico, o que ressalta a importância do acompanhamento às famílias que vivenciaram alguma situação de abuso.

Dell'Aglio e colegas (2011) também apontaram para a importância do atendimento de familiares não abusivos devido ao seu envolvimento com a situação de abuso, bem como para o atendimento do perpetrador como uma forma de prevenir o ciclo da violência. A necessidade de intervir com esse público também foi demarcada por Costa e colegas (2007), devido ao isolamento social que estende aos familiares. Muitas vezes, os membros familiares se esquivam de falar sobre e estar em situações que lembrem a violência, o que pode culminar em um isolamento dentro da própria família e da comunidade. Ainda, de acordo com Araújo (2002), na "ausência de um entorno social, familiar, institucional e jurídico que ampare a família após a denúncia, ela se vê sob ameaça do total abandono social" (p. 9).

Em decorrência das possíveis modificações na rotina familiar e do afastamento social, torna-se imprescindível o fortalecimento das redes de apoio aos familiares que se encontram em situações de suspeita de abusos sexuais. As redes de apoio social são compreendidas, neste artigo, como o "conjunto de sistemas e de pessoas significativas que compõem os elos de relacionamentos recebidos e percebidos do indivíduo" (Brito \& Koller, 1999, p.115). Estas abarcam desde "familiares, parentes, amigos e vizinhos (até) serviços de saúde, de assistência, a educação, os grupos de apoio e religiosos" (Brito, Nascimento, \& Rosa, 2018, p. 180). Ter uma rede fortalecida permite que os sujeitos melhorem a compreensão sobre suas possibilidades e suas adversidades, resultando em uma melhor saúde mental e na diminuição da ocorrência de psicopatologias (Brito \& Koller, 1999).

O fortalecimento da rede apoio, pode acontecer tanto por um movimento natural no meio intrafamiliar e na família extensa, ao prestar uma maior assistência, por exemplo, como por meio de auxílio profissional para que o familiar que oferece suporte possa estar mais preparado no amparo às vítimas (Santos \& Dell'Aglio, 2013). Tal constatação corrobora com o estudo realizado por Costa e colegas (2007) ao apontarem a necessidade de serem criados espaços de escuta qualificada em que o familiar poderá ser acolhido e expor suas dificuldades ou medos. Para exemplificar tal método, os autores apresentaram como alternativa, em seu estudo, o Grupo Multifamiliar, envolvendo atendimento grupal de quatro a cinco famílias.

Como apontado por Corcoran e Pillai (2008), em uma metanálise, terapias com crianças que havia sofrido abuso que envolviam os pais possuíam vantagens em relação a terapias focadas apenas nas crianças. Apesar disso, há uma escassez de dados e relatos de intervenções com os familiares de crianças envolvidas em situações de violência sexual no Brasil (Cunha \& Dutra, 2019; Dell'Aglio et al., 2011); ainda mais escassa é a literatura com perpetradores da violência (Costa et al., 2018) e seus familiares. É possível que alguns fenômenos que perpassam as famílias das vítimas (como a vergonha e o isolamento) também sejam relevantes para os familiares dos abusadores; no entanto, não encontramos estudos que lidam com estes últimos. A fim de preencher essa lacuna, o presente artigo tem como objetivo relatar o caso de atendimento psicossocial com base na abordagem da Análise do Comportamental da senhora $\mathrm{A}$, que se deu a partir de uma denúncia contra o seu marido, o senhor L, de abuso sexual vitimando crianças, no qual ainda não estava claro se o filho do casal havia sido uma das vítimas. A seguir destacamos alguns aspectos importantes das bases teóricas 
utilizadas para os atendimentos realizados com a senhora A ao longo de 25 atendimentos.

\section{Bases para o Atendimento Psicossocial}

De acordo com Macedo e Conceição (2017), o atendimento psicossocial pode ser considerado uma ferramenta fundamental no enfretamento do sofrimento decorrente da violência intrafamiliar. Esta abordagem visa o empoderamento dos indivíduos envolvidos, considerando seus históricos de vida e contexto social; o atendimento psicossocial, assim, envolve tanto aspectos psicológicos como sociais. Segundo Dell'Aglio e colegas (2011), os atendimentos psicossociais oferecem orientação sobre a natureza do abuso sexual, formas de lidar com o sofrimento das vítimas, estratégias de enfrentamento ao sentimento de culpa, fortalecimento com relação ao processo de denúncia, entre outros. Para alcançar tais objetivos, distintas abordagens psicológicas podem ser utilizadas, incluindo o Psicodrama, a Psicanálise, a Terapia CognitivoComportamental e a Análise do Comportamento, esta última utilizada no presente relato. Cabe ressaltar que, independente da abordagem terapêutica, é essencial proporcionar ao cliente um ambiente acolhedor e seguro (Lucânia, Valério, Barison, \& Miyazaki, 2009).

Wielenska (2012), com base em uma intervenção da Análise do Comportamento, propõe que é importante que o atendimento psicológico se apresente como uma escuta segura, qualificada, não punitiva e que apresente possibilidade de modificar $o$ sofrimento que está ali colocado. Desse modo, o cliente poderá se sentir mais à vontade para relatar aquilo que é mais aversivo (difícil de lidar) e importante para o contexto clínico. Nessa perspectiva, a partir do momento que o terapeuta é visto como uma figura capaz de auxiliar na diminuição do sofrimento, este passa a exercer funções de reforço, estímulo condicionado e estímulo discriminativo para o comportamento do cliente.

No decorrer dos atendimentos, o terapeuta busca uma relação significativa com o cliente, e coleta dados e informações que ajudem na compreensão dos comportamentos do cliente. A visão inicial do caso é compartilhada com o cliente pelo terapeuta, a fim de, em conjunto, traçarem metas e objetivos que tenham sentido para ambos; é a partir dessas metas e objetivos que o terapeuta busca estratégias iniciais a serem implementadas nos atendimentos. Ainda, uma das funções iniciais do terapeuta é diminuir o sofrimento do cliente frente à demanda que o levou a buscar ajuda profissional. Cabe ainda ressaltar que a queixa inicial (o que leva a cliente a buscar o atendimento) pode modificar-se ao longo do tempo, havendo então ajustes nos objetivos e metas traçados bem como nas estratégias utilizadas pelo terapeuta (Wielenska, 2012).

De acordo com Wielenska (2012), uma vez que a relação terapeuta-cliente está estabelecida e o primeiro passa a ser função para o comportamento do segundo, o terapeuta passa a mediar verbalmente à fala do cliente, possibilitando reflexões sobre os padrões comportamentais, favorecendo que as queixas iniciais produzam novos repertórios em seus clientes. Assim, a Análise do Comportamento tem como um de seus objetivos facilitar o relato de comportamentos encobertos dos clientes, propiciando que estes se atentem para questões antes despercebidas e dessa forma possam identificar os possíveis antecedentes funcionais. As análises funcionais são realizadas pelo terapeuta tanto nas interações ocorridas durante os atendimentos, como através dos relatos dos clientes, buscando ensinar ao cliente identificar comportamentos alternativos no seu dia-a-dia, promovendo o desenvolvimento de novas habilidades e repertórios comportamentais.

Essas estratégias da Análise do Comportamento podem ser aplicadas à diversas demandas, incluindo o atendimento psicossocial à familiares envolvidos em situações de abuso. Nesse artigo analisaremos o atendimento oferecido à esposa de um suposto abusador de crianças que chegou ao nosso projeto com dúvidas sobre a vitimização também de seu filho. Os atendimentos analisados nesse artigo perpassaram por esse 
viés da intervenção psicossocial, com base teórica da Análise do Comportamento. Inicialmente a cliente chegou ao atendimento com demandas relacionadas à denúncia de seu marido, porém, com o tempo, questões como a construção de uma rede de apoio, déficits em habilidades sociais, sofrimento causado pela denúncia, entre outros, apontaram padrões e repertórios comportamentais que necessitavam de intervenção. A seguir descrevemos, de acordo com a literatura trazida até o momento, os atendimentos que compuseram a experiência de estágio que resultou nesse artigo.

\section{Método Demanda}

$\mathrm{O}$ caso descrito neste artigo chegou como uma solicitação de outro aluno do curso de Psicologia ao relatar que era para uma senhora (A), 37 anos, do qual seu marido (senhor L), na época, havia sido acusado de cometer abuso sexual vitimando crianças. Todavia, além dos casos denunciados, a senhora A trazia a dúvida se seu filho (8 anos) também teria sido exposto a alguma situação de violência sexual por parte de seu marido. Nesse sentido, o atendimento da senhora A se iniciou a partir da demanda da cliente com relação à compreensão dos fatos relacionados à denúncia de abuso de seu marido e nas repercussões que a denúncia e o afastamento do marido da convivência família havia tido na convivência com o seu filho. Dentre as demandas iniciais da cliente estavam os aspectos emocionais fragilizados do filho após o afastamento familiar do pai e os sentimentos da própria cliente com relação às denúncias de abuso.

\section{Procedimentos}

Foram realizados um total de 25 atendimentos com a senhora $\mathrm{A}$ entre outubro de 2018 e julho de 2019, parte do projeto de estágio em psicologia "Apoio e Fortalecimento de Vínculos Familiares". Este projeto tem por objetivo realizar atendimentos psicossociais, individuais e/ou grupais, tanto com as crianças ou adolescentes que passaram por alguma violação de direitos, como com seus familiares, visto que tais situações resultam em uma fragilização dos laços familiares. O estágio está embasado em teorias da área de Psicologia Social e do Desenvolvimento, bem como caracterizado por atendimentos psicoterapêuticos com um enfoque em estratégias utilizadas na Análise do Comportamento. Os atendimentos com a senhora A foram realizados semanalmente com duração aproximada de 60 minutos. O estágio também contava com supervisões semanais, aonde eram realizadas discussões e orientações sobre os casos, após o relato dos atendimentos semanais. Dentre as estratégias utilizadas durante os atendimentos encontram-se o acolhimento inicial da demanda da cliente propiciando a ela um ambiente seguro e acolhedor, o delineamento de objetivos em conjunto a serem buscados com os atendimentos, o mapeamento de comportamentos indesejáveis e seus antecedentes nas interações durante os atendimentos e nos relatos trazidos pela cliente, e a busca de estratégias alternativas à esses comportamentos. Para auxiliar nessas estratégias foram utilizados recursos como atividades realizadas em conjunto durante a sessão (por exemplo, atividade em que a cliente desenhava o contorno de sua mão e escrevia dentro do contorno o que ela pensava sobre si e do lado de fora do contorno o que ela acreditava que os outros pensavam sobre ela, criação de histórias para discussão de estereótipos, atividades de organização da rotina, etc.). Além disso, algumas atividades a serem realizadas fora do contexto terapêutico foram incentivas e reforçadas durante os atendimentos, como a busca de ajuda com tarefas diárias (por exemplo, levar o filho para a escola), bem como o incentivo de atividades que promovessem a autorealização da cliente.

Neste projeto de estágio, os atendimentos são realizados individualmente com a criança ou adolescente, e em separado com pelo menos um responsável familiar. Havendo a possibilidade, amplia-se para um atendimento em grupo, em geral, de forma pontual, para que sejam compartilhados pontos em comum. Cabe ressaltar que o filho da 
senhora A já estava sendo acompanhado por um psicólogo em outro serviço público de saúde. Devido a isso, a senhora A foi atendida individualmente. Para o presente artigo, a cliente assinou o Termo de Consentimento Livre e Esclarecido autorizando a utilização dos dados clínicos para publicação. Foi garantido à participante o sigilo e confidencialidade de seus dados pessoais, garantido seu anonimato.

\section{Análise dos Dados}

A partir da demanda inicial da cliente, surgiram distintos temas que foram trabalhados ao longo dos atendimentos. Estes temas foram agrupados e divididos nos seguintes blocos temáticos, que serão analisados abaixo: (a) acolhimento e compreensão do contexto da demanda (seis atendimentos); (b) questões interpessoais após a denúncia (dor, sentimento de culpa, percepção de julgamento, etc.; quatro atendimentos); (c) relacionamento familiar, ampliação da rede de apoio e fortalecimento de vínculos (quatro atendimentos); (d) crenças pessoais com relação à capacidade de enfrentamento e de superação e identidade pessoal (cinco atendimentos); e (e) fortalecimento pessoal, rotina de trabalho e da vida familiar e busca e valorização de atividades de interesses da cliente (seis atendimentos).

\section{Resultados e Discussão}

A senhora A, com 37 anos quando iniciado o atendimento, morava com o filho de oito anos e com dois sobrinhos. Natural de outro estado brasileiro, no qual se encontrava boa parte de sua família, trabalhava como empregada doméstica na mesma casa há 17 anos. Apesar de os trâmites legais relacionados à denúncia de abuso por parte do marido (senhor L) ainda estarem em curso no momento dos atendimentos (ou seja, não havia uma confirmação de abuso), havia ocorrido uma quebra dos vínculos familiares, uma vez que o senhor $\mathrm{L}$ teve que sair de casa, devido a exposição dele e de sua família ao perigo, por morarem em um bairro de maior vulnerabilidade social, do qual a descoberta dos casos, por alguns, gerou ameaças direcionadas ao senhor L. Isso ocasionou um rompimento no convívio da criança com o seu pai e uma mudança na rotina familiar e situação econômica, semelhante ao constatado por Costa e colegas (2007) em seu estudo. Assim, havia um conflito familiar aversivo, o qual levou a senhora A a buscar ajuda profissional. O caso da senhora A se encaixava na proposta de estágio por se tratar de uma potencial situação de violação dos direitos e foi incluído nos atendimentos. A seguir discutiremos as principais temáticas trabalhadas com a senhora A durante os atendimentos.

\section{Acolhimento}

Nos atendimentos iniciais, a terapeuta estabeleceu os primeiros contatos com a cliente, buscando entender sua queixa inicial, bem como o seu contexto e a motivação para o atendimento. Com esse intuito, no primeiro encontro a terapeuta explicou sobre o que é o processo terapêutico, ressaltando a questão do sigilo e o fato de os atendimentos fazerem parte de um projeto de estágio que buscava auxiliá-la em suas demandas.

Ao ouvir as demandas e motivações para a procura por auxílio profissional, foi possível à terapeuta acessar as primeiras informações sobre a senhora $\mathrm{A}$, bem como compreender os impactos da denúncia do abuso na vida da cliente. Apesar de, ao relatar sobre o caso, a cliente tenha tido que reviver a experiência - situação possivelmente aversiva (Costa et al., 2007) - o espaço de atendimento mostrou-se destarte um ambiente acolhedor, representando a busca por soluções. Isto corrobora com o que Wielenska (2012) apontou, ao mencionar que a relação terapêutica irá se desenvolver a partir do momento em que o cliente visualiza no terapeuta a possibilidade de mostrar caminhos que amenizem o sofrimento que o trouxe ao atendimento. Com isso, torna-se evidente a importância dos atendimentos nesses momentos iniciais, em que os familiares ainda não estão em acompanhamento psicológico em 
nenhum outro serviço (Santos \& Dell'Aglio, 2010).

As três sessões seguintes abordaram os relatos envolvendo a denúncia de abuso e a história de vida da senhora A. Neste início do processo terapêutico ficou demarcado nas verbalizações da cliente a crença de que as denúncias de abuso contra seu marido, com o qual ela havia sido casada por doze anos, "teriam acontecido no tempo certo de Deus", por ela acreditar ter mais capacidade e preparação pra enfrentar a situação da denúncia naquele momento. A cliente trouxe outras histórias de sua vida e do início do casamento que ela associava a esse sentimento de preparação. Nesse sentido, a cliente verbalizou que se a denúncia tivesse ocorrido antes do seu filho nascer, possivelmente ela acreditava que não possuiria recursos para lidar com a pressão decorrente da situação.

A senhora A deixou evidente a centralidade do filho em sua vida, destacando as relações afetuosas entre ambos, e, também, o receio de a criança descobrir sobre a denúncia por intermédio de outras pessoas e de ter sua relação com o filho fragilizada, possibilidades essas que a deixava confusa sobre o momento de contar ao filho sobre a denúncia. Com essas demandas, a terapeuta trabalhou o medo de contar para o filho e a necessidade de desassociar a saída do senhor L de casa da figura da cliente (pois a criança chegou a verbalizar que se separaria da mãe, assim como o pai fez). Além disso, a terapeuta, junto com a senhora $\mathrm{A}$, pensaram em uma forma lúdica $\mathrm{e}$ acessível de dar algumas explicações para o filho. Como demarcado por Macedo e Conceição (2017), o atendimento psicossocial deve buscar soluções plausíveis e compreensíveis ao contexto e as possibilidades da cliente e, nesse caso, da criança.

Com o propósito de proteger a criança, a senhora A havia mudado sua rotina na tentativa de suprimir a falta que o pai fazia e afastar a criança de situações/convívios que poderiam o expor a situações em que a denúncia fosse revelada. Em vista disso, a cliente demonstrou um medo de que essas estratégias acentuassem o sofrimento do filho ainda mais, pois ela relatava constantemente mudanças de comportamento do filho, como alguns momentos de tristeza, agressividade, agitação, entre outros comportamentos, que a cliente associava à falta do pai. Estas observações são fruto de uma atenção intensificada à criança, que Hohendorff e colegas (2015) indicaram como sendo comuns em famílias que passaram por situações de abuso, devido a um maior foco nas variações comportamentais das crianças.

Com a maior vinculação da relação terapeuta-cliente, as queixas iniciais passaram a dar espaço a comportamentos considerados problemas para além da situação da denúncia de abuso diretamente, principalmente de ordem interna, sinalizando a passagem para o segundo bloco do processo terapêutico, que diz respeito às fragilizações das relações sociais da cliente $\mathrm{e}$ os sentimentos de inadequação em alguns ambientes. Entre relatos do convívio familiar, do qual ela apresentava pouca confiança nas pessoas por sentir-se traída (em razão das pessoas saberem do caso antes dela), a senhora A começou a expor o que a incomodava.

\section{Questões Interpessoais}

Alinhado ao que Marafon e Scortegagna (2017) trouxeram em seu estudo sobre os sentimentos que são desencadeados em pessoas e famílias que passam por alguma situação de abuso, a senhora A relatou se sentir envergonhada e "suja" devido às denúncias de abuso, principalmente no contexto da igreja. Esses sentimentos trazidos pela senhora A modificaram a forma com que ela se comportava nesse ambiente; além disso, a cliente verbalizou que desejava retornar a ser a pessoa que era antes da denúncia: brincar, manter conversas agradáveis e sorrir, sem sentir-se deslocada. A terapeuta buscou, nesses atendimentos, compreender se esses sentimentos já haviam comparecido em outros contextos; todavia, a cliente verbalizou que era algo relativo à denúncia e todas as mudanças percebidas pela cliente foram desencadeadas a partir deste evento. Com isso, a terapeuta buscou ajudar a cliente a discriminar o 
momento em que tais sentimentos apareceram, o significado dos sentimentos (principalmente o de "estar suja") e as consequências que eles traziam para a sua vida social.

Devido a sensação de inadequação sentida pela cliente, ela passou a frequentar menos o espaço religioso e a criar impedimentos para que as pessoas desse local a visitassem e estabelecessem contato. Nesse momento, a terapeuta fez uma intervenção sobre a necessidade de ela permitir ser vista/acessada, estabelecer vínculos, e buscar apoio em pessoas que estivessem se mostrando disponíveis. Esse padrão de comportamento relacionado ao afastamento social está de acordo com o destacado por Costa e colegas (2007); apesar disso, a cliente verbalizou que sempre foi "fechada", apontando que suas interações sociais não eram muito amplas, principalmente a partir do casamento. Assim, ficou estabelecido nesse momento um objetivo terapêutico de buscar alternativas para diminuir essa sensação de culpa e aumentar a rede de apoio. Cabe ressaltar, que a cliente trouxe essa mudança de comportamento na igreja também como consequência de dois estímulos aversivos presentes naquele contexto, que eram a presença da família de um dos casos de denúncia e o fato de algumas pessoas saberem sobre as denúncias. Esse isolamento/afastamento social e afetivo nos leva ao terceiro bloco.

\section{Rede de Apoio e Fortalecimento de Vínculos}

A partir da identificação do
enfraquecimento no relacionamento
interpessoal, dos vínculos familiares e por
consequência da rede de apoio da senhora A, a
terapeuta buscou construir junto com a cliente
estratégias para fortalecer esses pontos que
haviam se tornado frágeis a partir da tomada de
consciência da situação e do consequente
isolamento social. Assim, o isolamento social
foi entendido como uma tentativa de evitar
situações aversivas e constrangedoras, também
apontado por Costa e colegas (2007).

No decorrer dos atendimentos, a terapeuta observou que a senhora A apresentava uma rede de apoio limitada, sendo verbalizado, pela cliente, que essa era constituída por sua mãe (que morava em outro estado), uma cunhada, um sobrinho e a família a quem ela prestava serviços. A terapeuta refletiu com a cliente que a redução de sua rede de apoio devia-se em parte ao número de contextos reduzidos que ela frequentava, limitando-se a manter relacionamentos na igreja, família extensa e família onde trabalhava. Dessa forma, a ampliação de sua rede de apoio passava pela necessidade de expandir os contextos onde pudesse haver novas interações. A partir disso, a terapeuta dedicou as sessões a analisar os motivos pelos quais a cliente tinha a sua rede reduzida e a fomentar reflexões que buscavam valorizar a ampliação dos espaços de convivência da cliente. Inicialmente a cliente mostrou-se resistente, alegando não ter muitas pessoas com quem conversar e que não era um padrão comportamental dela.

Com vistas a intervir nesse padrão de resposta, devido a baixas habilidades sociais, a terapeuta passou a agir no sentido de auxiliar a cliente a identificar possíveis pessoas e ambientes que ela pudesse interagir, aplicando o que Wielenska (2012) chamou de reatividade diferencial. Esta seria a capacidade do terapeuta de mediar os discursos da cliente, de modo que esta consiga identificar seus próprios pontos de fragilidades e alternativas de mudança. Com isso, a senhora A passou a trazer atitudes diferentes com relação a sua interação social. Foram relatados, em sessão, os novos lugares frequentados, as pessoas que passou a conversar, e, até em alguns casos permitindo-se - mesmo que de forma ainda encoberta - falar para algumas pessoas sobre o sofrimento que ela estava passando devido à denúncia. Como exemplo disso, é possível destacar uma nova amizade com uma senhora que trabalhava no mesmo local da cliente, que aos poucos foi fazendo parte da rede de apoio dela. Todas essas verbalizações foram reforçadas pela terapeuta, visto que nessa relação terapeutacliente, o primeiro torna-se um estímulo ou um reforço para o comportamento do segundo (Wielenska, 2012). 
Com esse início de percurso, focado na abertura para as interações sociais, a percepção de uma fraca rede de apoio e vínculos sociais passou a ser observada com mais profundidade pela própria cliente. Com isso, a senhora A analisou em sua vida, fora do contexto clínico, o que estava sendo trabalhado nele, ponto demarcado por Wielenska (2012) como parte do processo terapêutico. Contudo, tais observações vieram marcadas por verbalizações como certo fracasso. A senhora A verbalizou estar fracassando em superar a situação, que em outras situações (história de contingências) ela tinha conseguido superar com mais facilidade, alegando inclusive que chegou ao atendimento de uma forma muito orgulhosa, com a crença de que venceria rápido a situação da denúncia também. Outro ponto demarcado pela senhora A foi o incômodo de estar na igreja, que ainda não havia se modificado, relatando a dificuldade de lidar com a presença de um dos casos de denúncia. Foram relatados também alguns conflitos com a família do ex-marido, que mantinha a crença de um retorno do casamento, situação inadmissível para a senhora A.

\section{Crenças Pessoais}

Nesses atendimentos, a terapeuta analisou, junto com a cliente, as verbalizações relacionadas ao fracasso pessoal. Primeiro, a terapeuta e a cliente relembraram o percurso que a senhora A tinha feito até o momento na terapia, o comprometimento com os atendimentos, as mudanças já ocorridas, os ganhos comportamentais, dentre outros pontos. A terapeuta sinalizou também o fato de que, com o avanço do processo terapêutico, outras questões, diferentes das que a levaram até o atendimento, foram emergindo, fazendo com que a senhora A tivesse que ampliar o olhar para outras situações. Isto foi discutido no intuito de mostrar o quanto ela já tinha progredido, fazendo uma diferenciação do início até o momento, e, fornecendo estímulos para que ela progredisse nas mudanças ainda necessárias.

Além disso, a terapeuta trabalhou com a cliente uma mudança de pensamento sobre o julgamento das outras pessoas de sua convivência. Uma mudança na forma como ela passou a se portar na igreja ficou evidente (demonstrada no aumento da frequência nos cultos da noite), ao ser analisado e reafirmado pela senhora A sua ausência de culpa e de responsabilidade nas denúncias de abuso e o fato de as pessoas não necessariamente terem conhecimentos sobre a denúncia.

Orientada por uma observação feita em supervisão sobre a necessidade de se trabalhar a identidade pessoal da cliente, a terapeuta realizou uma atividade com o intuito de diferenciar o que a cliente pensava sobre si e o que ela acreditava que os outros pensavam sobre ela. Inicialmente, a cliente apresentou certa resistência a atividade por ser desafiador pensar sobre si mesma, visto que demanda um autoconhecimento, e, principalmente pensar em algo que não fosse relacionado à situação da denúncia (o que de fato reverberou em suas pontuações na atividade). Por exemplo, a cliente apontou para mudanças de comportamentos, como antes da denúncia ser extrovertida, brincalhona, e, depois estar mais fechada e ter que superar a situação. Todavia, pontos positivos também se fizeram presentes, principalmente na segunda sessão em que a atividade foi trabalhada, quando perguntada sobre o que seus familiares, empregadores e filho pensavam dela. Neste momento, foram destacadas características como: "alegre", "trabalhadora", "bonita", "meio maluca", "despachada", "interessante" e "importante".

Com a diminuição dos episódios de tristeza trabalhados nos atendimentos, alguns aspectos da vida diária e sobrecargas, geradas principalmente pela mudança da rotina familiar, começaram a aparecer com mais frequência. A senhora A passou a ter uma rotina mais agitada e focada na criança, variando entre o trabalho, atividades domésticas e atividades da e com a criança. Desse modo, apareceu, em sessão, incômodos relacionados a tudo o que demandava mais esforço e tempo. Todavia, verbalizações sobre estar focada nas atividades, para evitar pensamentos aversivos, também foram trazidas pela cliente. Como afirmaram 
Costa e colegas (2007), é comum ocorrer uma mudança na rotina familiar após uma quebra dos vínculos familiares gerados por uma denúncia ou suspeita de abuso.

\section{Fortalecimento Pessoal}

A partir do exposto nas sessões anteriores, ao longo dos atendimentos, a terapeuta buscou trabalhar com a cliente uma organização para sua rotina, na tentativa de encaixar momentos de descanso e cuidado com ela mesma. Além disso, a terapeuta buscou reforçar a assertividade da senhora $\mathrm{A}$ ao se posicionar com relação às propostas que surgiam e que a deixariam cansada. A cliente trouxe ao longo dos atendimentos poucas atividades que a satisfaziam. Então, a terapeuta buscou ampliar o olhar dela para atividades que a trouxessem prazer, sem necessariamente estar ligadas às atividades de seu filho; a terapeuta trabalhou a ideia de que por mais prazeroso que fosse estar em atividades em prol do filho, eram atividades que pouco geravam satisfação pessoal. Cabe frisar, que o atendimento da senhora A encontra-se atualmente em andamento.

\section{Considerações Finais}

Este trabalho contribui para a literatura ao relatar o atendimento psicossocial de um familiar (a esposa) de uma pessoa envolvida em uma denúncia de abuso sexual. As questões trazidas nos atendimentos aqui relatados corroboram com a literatura sobre abusos sexuais, suporte materno, rede de apoio e fortalecimento de vínculos. Prestar atendimento à familiares em contexto de fragilização de vínculos é extremamente importante, visto que as famílias muitas vezes encontram-se desamparadas, vivenciando episódios de isolamento social e sem pontos de apoio para recorrer (Araújo, 2002; Costa et al., 2007; Santos \& Dell'Aglio, 2010). Este fato é também confirmado pela alta demanda por atendimento às crianças, adolescentes e seus familiares que passaram por situação de violações acolhidos no projeto de estágio aqui apresentado.
Cabe ressaltar que, apesar da escassez de literatura abordando as questões enfrentadas por familiares do agressor, as demandas trazidas pela cliente nesse estudo foram semelhantes as encontradas na literatura com relação à familiares de vítimas de abuso sexual, incluindo o sentimento de isolamento social e a vergonha; essas semelhanças podem estar relacionadas ao fato de haver dúvidas por parte da cliente sobre um possível abuso de seu filho no caso aqui apresentado. Apesar disso, em estudo futuros, há que se buscar conhecer as peculiaridades dos familiares de acusados e perpetradores da violência. Ademais, o caso aqui apresentado corrobora com as concepções de Santos e Dell'Aglio (2010) ao apontarem a necessidade de existirem serviços que acompanhem as famílias e as vítimas de abusos enquanto os trâmites legais estão em andamento, uma vez que, por ainda não terem sido acolhidos por algum serviço, podem se sentir sozinhos e desamparados. Dessa maneira, a escuta qualificada e não punitiva (Wielenska, 2012), e, o atendimento psicossocial tornam-se elementos imprescindíveis nesse momento.

Em geral, pudemos perceber como um evento não normativo (a denúncia de abuso sexual infantil, sendo o acusado o marido) possuiu impacto profundo em diversas esferas da vida da cliente, como nas relações com os outros, acesso à rede de apoio, crenças e identidade pessoais, dentre outros. Neste sentido, é notável o alcance dos objetivos dos atendimentos aqui apresentados, fortalecendo os familiares, tornando-se apoio e fortalecendo os vínculos intra e extrafamiliares. As mudanças percebidas ao longo dos atendimentos são de importante ressalva, como visto nas falas da própria cliente: "eu revivi", "eu tenho o remédio para minha própria dor", "hoje a dor é menor", "hoje eu sei conversar com meu filho", etc. Assim, os ganhos comportamentais nas relações interpessoais e na forma de lidar com a demanda inicial foram perceptíveis. Isto ressalta um processo de implicação e empoderamento que trouxe resultados positivos, apesar de ainda haver espaço para progresso em algumas áreas, como 
a relação com a família extensa, maior fortalecimento da rede de apoio e o estabelecimento de relações de confiança. Além disso, a terapia poderia ser fortalecida através de um acompanhamento em conjunto com o filho. Destacamos, no entanto, que o processo terapêutico continua em andamento.

Por fim, com o presente trabalho esperamos contribuir para o conhecimento e práticas voltadas para os envolvidos em situações de denúncias de violência sexual, tais como familiares do acusado. Com isso ressaltamos a importância de compreender de modo sistêmico os contextos e relações em que estão inseridos não apenas as vítimas e os acusados, mas também seus familiares. Destacamos também a importância do apoio social e do fortalecimento da vinculação familiar no processo de enfrentamento da situação de denúncia de abuso, bem como a importância do apoio profissional como fatores protetivos frente a situações de vulnerabilidade.

\section{Referências}

Araújo, M. F. (2002). Violência e abuso sexual na família. Psicologia em

Estudo, 7(2), 3-11. doi: 10.1590/S141373722002000200002

Beck, J. (2014). Terapia cognitivocomportamental: Teoria e prática ( $2^{\mathrm{a}} \mathrm{ed}$., S. M. da Rosa, Trad). Porto Alegre: Artmed.

Brito, C. O., Nascimento, C. R. R., \& Rosa, E. M. (2018). Conselho tutelar: rede de apoio socioafetiva para famílias em situação de risco?. Pensando familias, 22(1), 179-192. Recuperado de http://pepsic.bvsalud.org/scielo.php?script= sci_arttext\&pid=S1679494X2018000100014\&lng=pt\&tlng=pt

Brito, R. C., \& Koller, S. H. (1999). Desenvolvimento humano e redes de apoio social e afetivo. In A. M. Carvalho (Org.), O mundo social da criança: Natureza e cultura em ação. (pp. 115-130). São Paulo: Casa do Psicólogo.

Campos, M., Schor, N., Anjos, R., Laurentiz, J., Santos, D., \& Peres, F. (2005). Violência Sexual: integração saúde e segurança pública no atendimento imediato à vítima. Saúde e Sociedade, 14(1), 101-109. doi: 10.1590/S0104-12902005000100011

Corcoran, J., \& Pillai, V. (2008). A metaanalysis of parent involved treatment for child sexual abuse. Research on Social Work Practice, 18(5), 453-464. doi: $10.1177 \% 2 F 1049731507313980$

Costa, L. F., Penso, M. A., Rufini, B. R., Mendes, J. A. A., \& Borba, N. F. (2007).
Família e abuso sexual: silêncio e sofrimento entre a denúncia e a intervenção terapêutica. Arquivos Brasileiros de Psicologia, 59(2), 245-255. Recuperado de http://pepsic.bvsalud.org/scielo.php?script= sci_arttext\&pid=S180952672007000200013\&lng=pt\&tlng=pt

Costa, L., Rocha, C., \& Cavalcante, L. (2018). Características biopsicossociais entre acusados de agressão sexual contra crianças/adolescentes em contextos intra e extrafamiliar. Temas em Psicologia, 26(1), 283-295. doi: http://dx.doi.org/10.9788/tp2018.1-11pt

Cunha, G. G., \& Dutra, E. M. S. (2019). Um olhar fenomenológico para mães de crianças vítimas de abuso sexual: uma revisão de literatura. Revista da Abordagem Gestáltica, 25(1), 103-110. doi: 10.18065/RAG.2019v25.10

De Antoni, C., Yunes, M., Habigzang, L., \& Koller, S. (2011). Abuso sexual extrafamiliar: percepções das mães de vítimas. Estudos de Psicologia (Campinas), 28(1), 97-106. doi: 10.1590/S0103-166X2011000100010

Dell'Aglio, D., Moura, A., \& Santos, S. (2011). Atendimento a mães de vítimas de abuso sexual e abusadores: considerações teóricas e práticas. Psicologia Clínica, 23(2), 53-73. doi: 10.1590/S010356652011000200005

Florentino, B. R. B. (2015). As possíveis consequências do abuso sexual praticado contra crianças e adolescentes. Revista de 
Psicologia, 27 (2), 139-144.

doi:10.1590/1984-0292/805

Hohendorff, J., Santos, S. S., \& Dell'Aglio, D.

D. (2015). Estudo de caso sobre a revelação da violência sexual contra meninos.

Contextos Clínicos, 8(1), 46-54. doi:

$10.4013 / \mathrm{ctc} .2015 .81 .05$

Lei n. 8.069, de 13 de julho de 1990. Dispõe

sobre o Estatuto da Criança e do

Adolescente e dá outras providências.

Recuperado de

http://www.planalto.gov.br/ccivil_03/Leis/ L8069.htm

Lima, C. M. (2018). Abuso sexual de crianças e adolescentes e inclusão social. Educação: Saberes e Práticas, 7(1). Recuperado de http://revistas.icesp.br/index.php/SaberesPr atica/article/view/345

Lima, J. A., \& Alberto, M. A. P. (2016).

Urgências psicológicas no cuidado às mães em casos de abuso sexual intrafamiliar.

Estudos de Psicologia (Natal), 21(3), 337-

347. doi: $10.5935 / 1678-4669.20160032$

Lucânia, E. R., Valério, N. I., Barison, S. Z.

P., \& Miyazaki, M. C. O. S. (2009).

Intervenção cognitivo-comportamental em violência sexual: Estudo de caso.

Psicologia em Estudo, 14(4), 817-826. doi: 10.1590/S1413-73722009000400022

Macedo, E. O. S., \& Conceição, M. I. G. (2017). Atendimento psicossocial a crianças e adolescentes em situação de violência: O psicólogo e a rede de atenção. Pesquisas e Práticas Psicossociais, 12(1), 129-146. Recuperado em de http://pepsic.bvsalud.org/scielo.php?script= sci_arttext\&pid=S180989082017000100010\&lng $=p t \& t \operatorname{lng}=p t$

Marafon, P., \& Scortegagna, S. A. (2017). Suporte materno mediante o abuso sexual infantil: Revisão de literatura. Estudos Interdisciplinares em Psicologia, 8(1), 119134. doi: $10.5433 / 2236-$ $\underline{6407.2017 \mathrm{v} 8 \mathrm{n} 1 \mathrm{p} 119}$
Ministério da Mulher, da Família e dos Direitos Humanos (2019). Disque direitos humanos: Relatório 2018, 13-18, Brasília, DF. Retirado de

https://www.mdh.gov.br/informacao-aocidadao/ouvidoria/balanco-disque-100

Pincolini, A., \& Hutz, C., (2014). Abusadores sexuais adultos e adolescentes no sul do Brasil: pesquisa em denúncias e sentenças judiciais. Temas em Psicologia, 22(2), 301312. doi: 10.9788/TP2014.2-03

Pincolini, A., Hutz, C., \& Laskoski, L. (2012). Caracterização da Violência Sexual a partir de Denúncias e Sentenças

Judiciais. Psicologia em Pesquisa, 6(1), 1928. Recuperado de http://pepsic.bvsalud.org/scielo.php?script= sci_arttext\&pid=S1982$12472012000100004 \& \operatorname{lng}=\mathrm{pt} \& \operatorname{tlng}=\mathrm{pt}$

Santos, S., \& Dell'Aglio, D. (2010). Quando o silêncio é rompido: o processo de revelação e notificação de abuso sexual infantil. Psicologia \& Sociedade, 22(2), 328-335. doi: 10.1590/S010271822010000200013

Santos, S., \& Dell'Aglio, D. D. (2013). O processo de revelação do abuso sexual na percepção de mães. Psicologia: teoria e prática, 15(1), 50-64. Recuperado de http://pepsic.bvsalud.org/scielo.php?script= sci_arttext\&pid=S151636872013000100004\&lng=pt\&tlng=pt

Vieira, M. S. (2018). Violência sexual contra meninas: Do silêncio ao enfrentamento. Revista Libertas, 18 (2), 101-116. doi: 10.34019/1980-8518.2018.v18.18596

Wielenska, R. C. (2012). O papel da relação terapeuta-cliente para a adesão ao tratamento e à mudança comportamental. In N. B. Borges, F. A. Cassas, \& Cols. (Org.), Clínica analítico - comportamental: Aspectos teóricos e práticos. $\left(1^{\mathrm{a}} \mathrm{ed} ., \mathrm{pp}\right.$. 160-165). Porto Alegre: Artmed. 


\section{Dados sobre os autores:}

- Simone de Souza Santos: Psicóloga pela Universidade Federal do Espírito Santo (UFES). Interessada pelo suporte teórico da Psicologia Social, direcionou sua trajetória acadêmica por espaços como Acolhimento Institucional para população adulta em situação de rua, atendimento psicossocial objetivando fortalecimento de vínculos familiares e projeto de extensão voltado à adolescentes de uma comunidade vulnerável socialmente.

- Edinete Maria Rosa: completou o doutorado em Psicologia Social na Universidade de São Paulo (USP) e foi pesquisadora de pós-doutorado na Universidade da Carolina do Norte em Greensboro (Estados Unidos). Atualmente é professora do Departamento de Psicologia Social e do Desenvolvimento da Universidade Federal do Espírito Santo (UFES).

- Elisa Avellar Merçon-Vargas: completou o mestrado em Psicologia Social e do Desenvolvimento na Universidade Federal do Espírito Santo (UFES) e o doutorado em Desenvolvimento Humano e Estudos da Família na Universidade da Carolina do Norte em Greensboro (Estados Unidos). Atualmente é pós-doutoranda na UFES. 